\title{
Leukaemia cutis as a specific skin involvement in chronic myelomonocytic leukaemia and review of the literature
}

\author{
Yanhong Qiao ${ }^{1 \#}$, Jinli Jian ${ }^{1 \#}$, Lijuan Deng ${ }^{1}$, Hongjuan Tian ${ }^{1}$, Bei Liu ${ }^{1,2}$ \\ ${ }^{1}$ The First Clinical Medical College, Lanzhou University, Lanzhou, China; ${ }^{2}$ Department of Hematology, The First Affiliated Hospital, Lanzhou \\ University, Lanzhou, China \\ Contributions: (I) Conception and design: B Liu, Y Qiao; (II) Administrative support: B Liu; (III) Provision of study materials or patients: B Liu, Y \\ Qiao; (IV) Collection and assembly of data: Y Qiao, L Deng; (V) Data analysis and interpretation: Y Qiao, J Jian, H Tian; (VI) Manuscript writing: \\ All authors; (VII) Final approval of manuscript: All authors. \\ \#These authors contributed equally to this work. \\ Correspondence to: Bei Liu. Doctorate, Professor, The First Affiliated Hospital, Lanzhou University, 1 Donggangxilu Street, Lanzhou, Gansu 730000, \\ China. Email: liubeiff@163.com.
}

\begin{abstract}
The skin involvement of myeloid leukaemia is conventionally divided into specific malignant lesions and non-specific benign lesions, and these categories are also applicable in chronic myelomonocytic leukaemia (CMML). According to the 2016 World Health Organization (WHO) classification of tumours of haematopoietic and lymphoid tissues, CMML is defined as a myeloid neoplasm with characteristics of myelodysplastic syndrome (MDS) and myeloproliferative neoplasms (MPNs). As a specific cutaneous sign of extramedullary infiltration, leukaemia cutis (LC) is a rare occurrence in patients with CMML, and only approximately 89 cases have been reported in the literature thus far. The clinical features of LC are varied, and LC in CMML exhibits heterogeneous histopathologic features, with manifestations as cutaneous nodules or papules that are composed of blast cells showing either granulocytic or monocytic differentiation. Skin biopsy and further immunohistochemical examination are essential at the time of diagnosis to evaluate pathological type and determine the clinical course. Generally, once diagnosed as LC in CMML, this unusual skin lesion might be an indicator of transformation to acute myeloid leukaemia (AML) and is associated with a poor prognosis. The main treatment is allogeneic stem cell transplantation (ASCT). Therefore, early diagnosis and accurate identification have important therapeutic and prognostic significance in CMML patients with skin infiltration.
\end{abstract}

Keywords: Chronic myelomonocytic leukaemia (CMML); skin involvement; leukaemia cutis (LC); prognosis; extramedullary infiltration

Submitted Dec 19, 2019. Accepted for publication Jul 08, 2020.

doi: $10.21037 /$ tcr-19-2882

View this article at: http://dx.doi.org/10.21037/tcr-19-2882

\section{Introduction}

CMML often presents with sustained ( $>3$ months) peripheral blood $(\mathrm{PB})$ monocytosis $\left[\geq 1 \times 10^{9} / \mathrm{L}\right.$; monocytes $\geq 10 \%$ of the white blood cell (WBC) count] along with dysplastic features in the bone marrow (BM) and has an inherent risk for transformation to acute myeloid leukaemia (AML). CMML is now subdivided into three types (CMML-0, 1, 2) depending on the number of blasts and promonocytes found in the $\mathrm{PB}$ or BM. Since CMML is a subtype of MDS or MPN, it is divided into myelodysplastic CMML (MD-CMML, WBC $<13 \times 10^{9} / \mathrm{L}$ ) and proliferative CMML (MP-CMML, WBC $\geq 13 \times 10^{9} / \mathrm{L}$ ) based on the WBC count, according to the French-American-British (FAB) recommendations (1). The skin involvement of CMML can be both specific, such as neoplastic infiltration (leukaemia cutis, LC), and non-specific (e.g., opportunistic infections, neutrophilic and granulomatous dermatoses, and 
drug reactions) (2). LC is defined as a specific cutaneous involvement of myeloid or lymphoid tumour cells, resulting in clinically identifiable cutaneous lesions, which mostly occur in patients with AML and rarely in those with chronic myeloproliferative diseases (3), especially CMML. The occurrence of skin lesions may be the result of various features of CMML and heralds its progression to acute leukaemia. In this article, we review the literature and discuss the incidence, clinical characteristics, diagnosis, pathological features, treatment and prognostic value of LC in CMML. We present the following article in accordance with the Narrative Review reporting checklist (available at http://dx.doi.org/10.21037/tcr-19-2882).

\section{Data source}

We searched the key subject terms "chronic myelomonocytic leukaemia", "skin involvement", and "leukaemia cutis" in the PubMed database from 1983 to September 2019. Most of the articles were case reports, from which we collected data for further discussion, and all cases were diagnosed as CMML with LC (Table 1).

\section{Epidemiology and pathogenesis}

LC is a rare specific skin involvement of leukaemia occurring in $10 \%$ to $15 \%$ of patients with $\mathrm{AML}$; most cases occur in patients with AML, especially acute monocytic leukaemia, and approximately $1 \%$ of patients with chronic lymphocytic leukaemia (3). Moreover, the incidence of LC seems to be higher among children than adults, particularly in infants with myeloid leukaemia $(3,28,29)$. In contrast, CMML mostly occurs in the elderly population, with an incidence of approximately 4 cases per 100,000 persons per year. The median age ranges from 71 to 74 years, with a predominance in males, and the male-to-female ratio is approximately 1.5-3:1 (1). Due to the low incidence of CMML, skin involvement in CMML is relatively rare, especially LC. Bénet et al. reported 173 patients with myeloid leukaemia with LC from their database of 9 centres in France between 1992 and 2008; only 19 (11\%) patients had CMML (30). In Mathew's study, 11 of 108 patients (10\%) with CMML were diagnosed with LC at the Moffitt Cancer Center [2003-2010] (17). The epidemiology of LC in CMML is not well known at present; only 24 publications about LC occurring in CMML were identified when we searched the English literature between 1983 and 2019 (7-30). The available data from these 89 previous cases of CMML with LC are summarized in Table 2. The actual incidence might be slightly higher than the number of cases collected in this study because the failure to perform skin biopsy may lead to the misdiagnosis of LC as other types of lesions. There were 67 males and 22 females, with a mean age of 70 years (range, 5 to 95 years). Overall, LC can precede, follow or occur concomitantly with systemic leukaemia, as well as CMML, and all three have been described in isolated or multiple case studies. In general, $62.9 \%(56 / 89)$ of the cases occur after a diagnosis of CMML has been established, whereas nearly one-third of the skin lesions occur simultaneously at diagnosis. Rarely (5.7\% of cases), skin involvement occurs several months or years before $\mathrm{PB}$ or $\mathrm{BM}$ abnormalities are detected and before the onset of systemic symptoms; this is so-called "aleukaemic leukaemia cutis", which eventually develops into AML and has a relatively worse prognosis $(31,32)$.

The molecular pathological mechanism underlying the invasion of leukaemic cells into the skin is not very clear so far. The expression of T-cell antigens and CD56 on blast cells may be associated with cutaneous involvement $(33,34)$. In a study in 2008, Cho-Vega and colleagues proposed the hypothesis that memory T-cells, different chemokine receptors and specific adhesion molecule receptors might play an intermediate role in causing leukaemic cells to migrate into the dermis; this hypothesis still needs clarification through further research (3).

\section{Clinical characteristics}

Patients with CMML may present with a variety of cutaneous manifestations at any stage of the disease. The skin lesions are generally divided into specific and nonspecific lesions: the former is the result of the direct invasion of neoplastic leukocytes (leukaemia cells) into the epidermis, dermis, or subcutaneous tissues, and includes LC and its subcategory leukaemic vasculitis, which involves leukaemic cells infiltrating and destroying blood vessels within the dermis (2). Since LC occurs in different types of leukaemia, it can have various clinical appearances $(18,20,26)$. We found that the majority of these 89 CMML cases in the literature presented as violaceous or red-brown nodules, papules, plaques of varying sizes, and maculopapular rash, while the number of cases with painful or pruritic rash, pustules and ulcers were fewer. Furthermore, the skin lesions were localized or disseminated and could be located in any site of the body, mostly involving the trunk and lower extremities, followed by the face, arms, scalp 


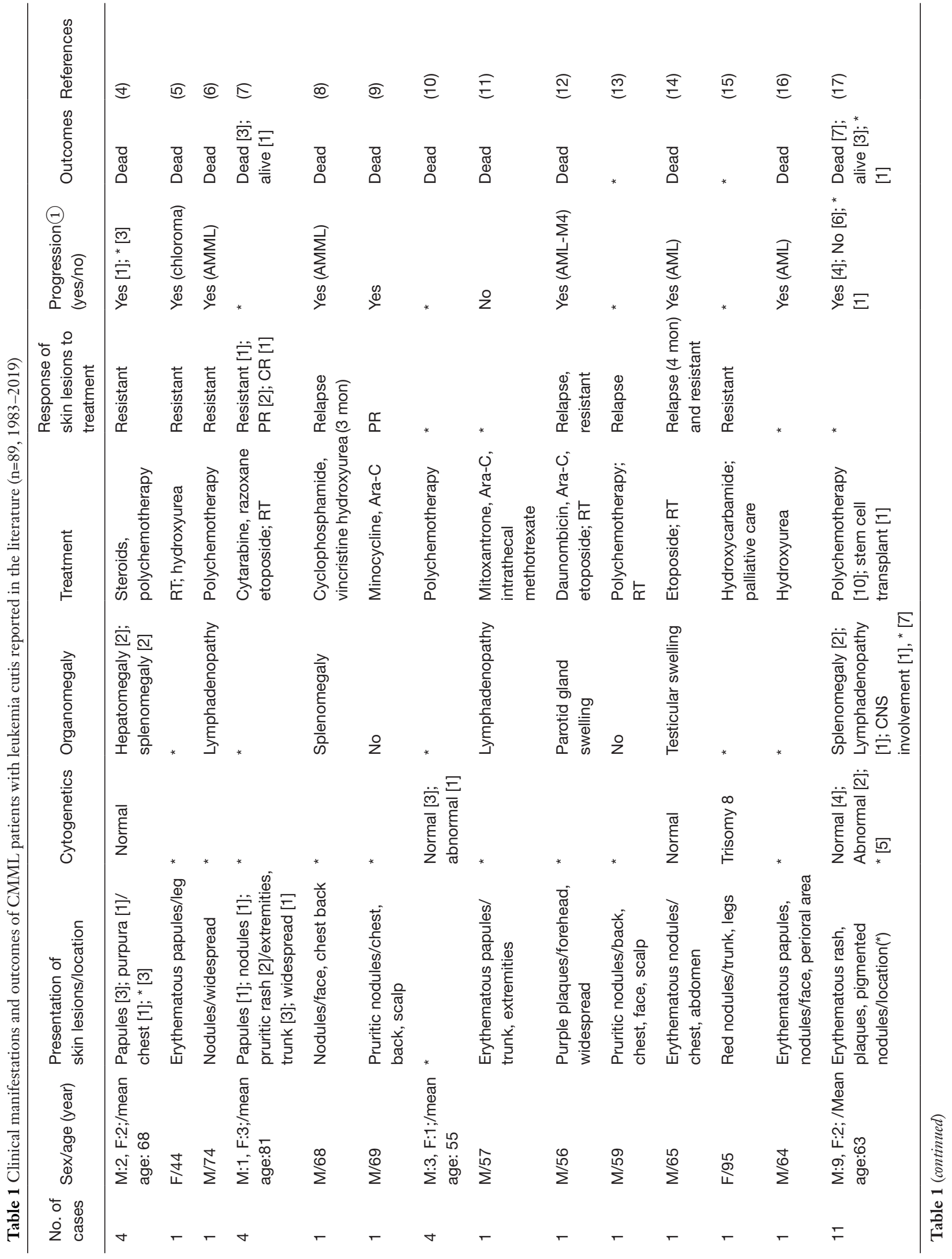




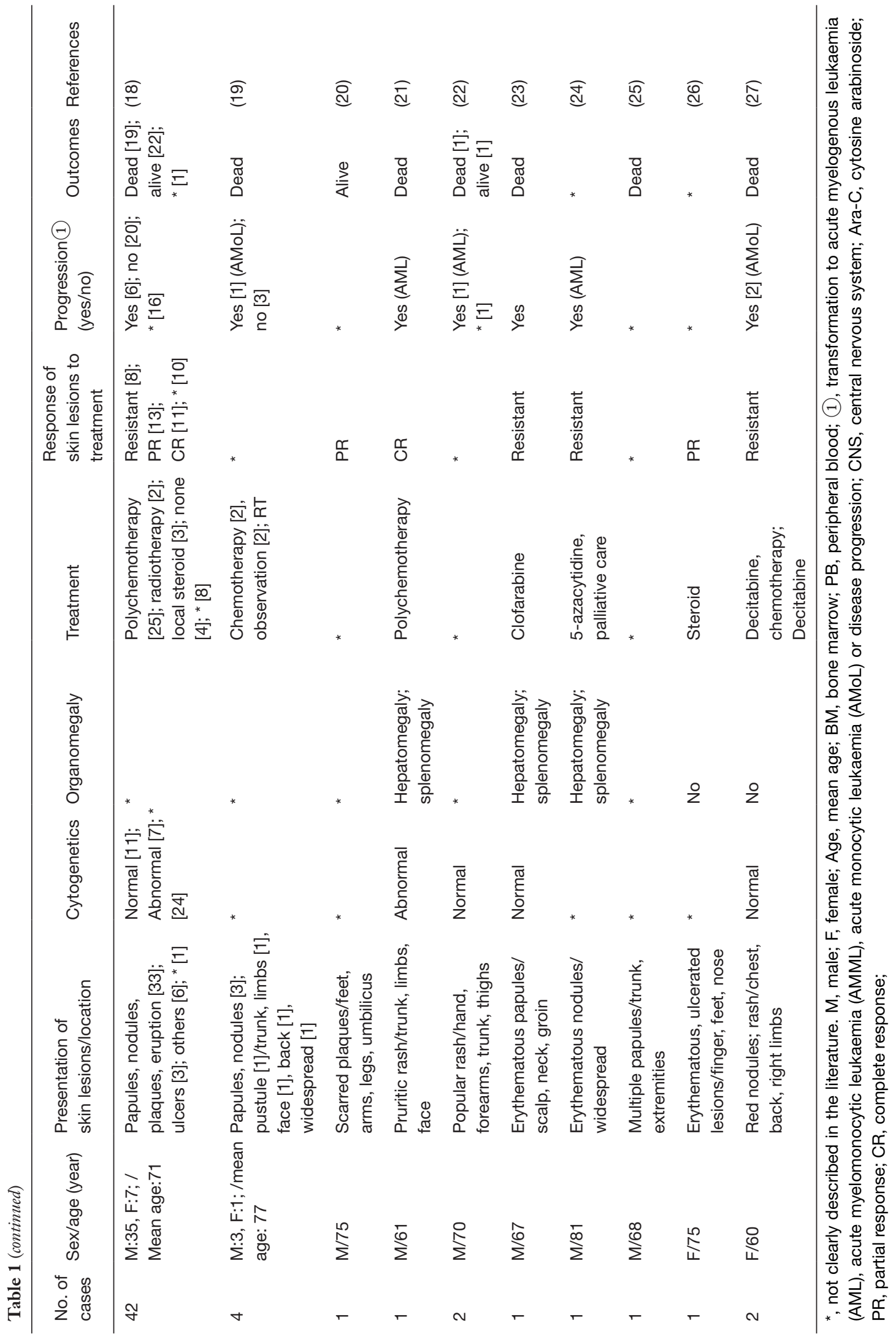


Table 2 Summary of the main clinical data of 89 cases in the literature

\begin{tabular}{lc}
\hline Main clinical data & $\begin{array}{c}\text { All patients, } \\
\mathrm{n}(\%)\end{array}$ \\
\hline Total of the number of cases & 89 \\
Median age(years) & 70 \\
Sex & \\
Male & $67(75.3)$ \\
Female & $22(24.7)$ \\
Common findings of presentation & \\
Papules, nodules, or plaque & $76(85.4)$ \\
Ulcer & $4(4.5)$ \\
Pustule & $1(1.1)$ \\
Others (such as unique subcutaneous swelling) & $6(6.7)$ \\
Data not available & $2(2.2)$ \\
Common findings of location & \\
Extremities, trunk, chest or widespread & $72(80.9)$ \\
Other locations (face, nose, scalp, neck, feet, & $10(11.2)$ \\
finger) & \\
Data not available & $26(29.2)$ \\
Before diagnosis of CMML & $56(62.9)$ \\
Concomitant with diagnosis of CMML & \\
\hline & \\
\hline
\end{tabular}

Table 2 (continued)

and neck (Table 2). Non-specific skin lesions occur in up to $40 \%$ of patients with leukaemia (3), covering a variety of complex manifestations that are mostly attributable to a number of nonmalignant causes: infectious aetiologies, such as chronic fungal infections (thrush), bacterial infections (Staphylococcus aureus) (35) and viral infections (berpes simplex); connective tissue disorders, such as systemic lupus erythematosus, sarcoidosis, and neutrophilic dermatoses [Sweet syndrome (36) and pyoderma gangrenosum $(37,38)]$; and drug eruptions, resulting in unidentifiable cutaneous lesions that make it difficult to clinically distinguish LC from other skin lesions. Of course, a similar distribution of skin lesions should also be considered, which may the result of neoplastic factors, such as the metastasis of visceral
Table 2 (continued)

\begin{tabular}{lc}
\hline Main clinical data & All patients, \\
$\mathrm{n}(\%)$
\end{tabular}

CMML, chronic myelomonocytic leukaemia.

malignancies, lymphoma, Kaposi sarcoma, basal cell carcinoma and squamous cell carcinoma (39). Skin biopsy and further immunohistochemical examinations are the main differential diagnosis tools at present $(3,39,40)$. In addition, we found that most patients with LC generally also have other types of extramedullary symptoms, which may be associated with a worse prognosis and shorter survival (41). The most common locations include the liver, spleen and lymph nodes, whereas the involvement of the central nervous system and other sites are rare (Table 2).

\section{Diagnosis}

The diagnosis of LC is mainly based on the clinical characteristics and histopathologic features of the skin lesions, including the cytologic features, and the immunophenotype of the infiltrative tumour cells is the 


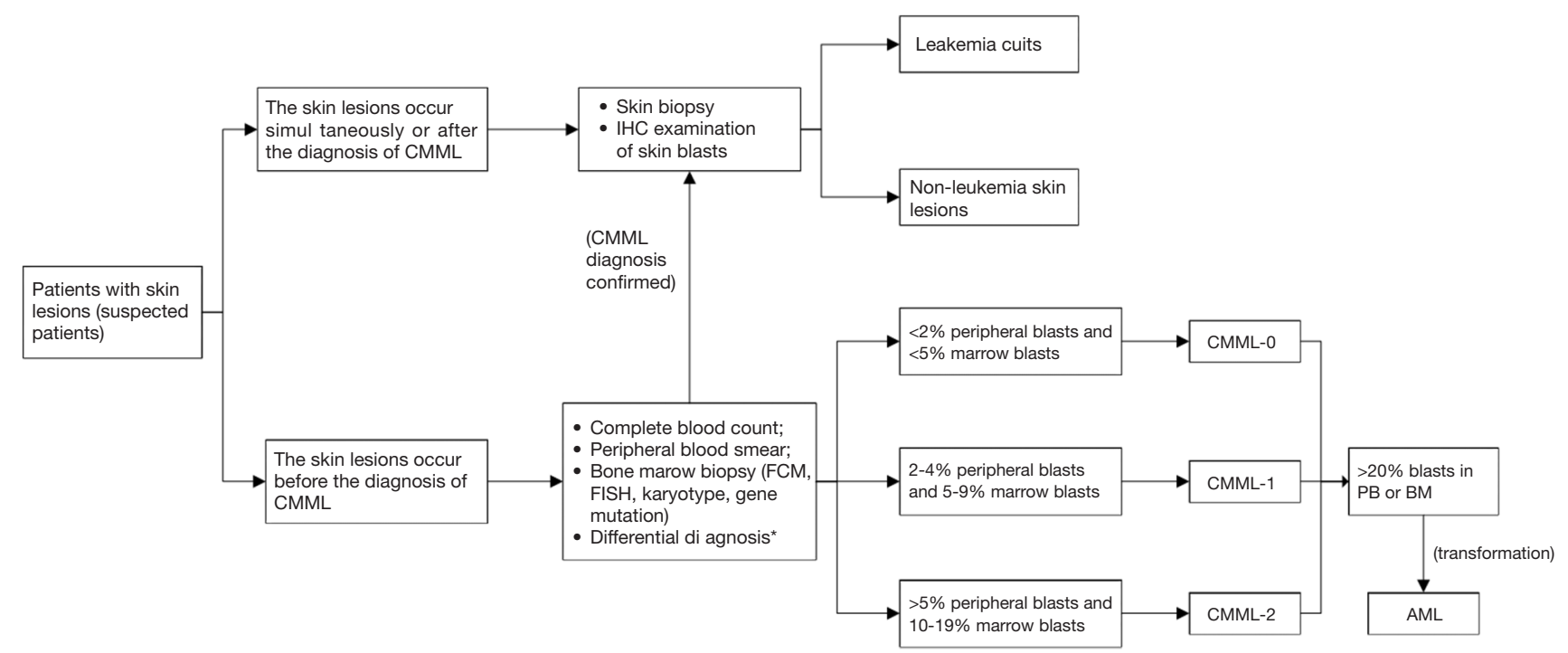

Figure 1 Flow chart with a brief description of the diagnostic process for CMML patients with skin involvement. *, 2016 WHO recommended diagnostic criteria for CMML. IHC, immunohistochemistry; FCM, flow cytometry; FISH, fluorescence in situ hybridization; AML, acute myeloid leukemia; CMML, chronic myelomonocytic leukaemia.

most important, as it can further distinguish CMML from other subtypes of leukaemia. In addition, medical history, PB findings, immunohistochemistry, flow cytometry, fluorescence in situ hybridization, and molecular analysis of BM biopsy are also helpful in confirming the diagnosis $(25,40)$. However, in the absence of a clinical history of leukaemia, which we called aleukaemic LC, conventional diagnostic tools for haematologic malignancies have little value, and morphologic and immunohistochemical analysis of the skin lesions are critical for the diagnosis (42). Similarly, a recently published review suggested that skin biopsy and histopathological examination should be performed regardless of whether the patient had leukaemia and even if the lesion appears to be a non-specific eruption, to rule out skin involvement by leukaemic cells (40). Therefore, we always make every effort to obtain a tissue diagnosis unless there is a contraindication in the clinical course. The diagnostic process is shown in the Figure 1.

\section{Histopathologic features}

As a direct invasion of malignant myeloid blasts into the skin, LC in CMML exhibits heterogeneous histopathologic features, with manifestations as cutaneous nodules or papules that are composed of blast cells showing either granulocytic or monocytic differentiation (42). In the largest retrospective analysis study to date, Vitte et al. divided 42 skin biopsy specimens of CMML patients with LC into four distinctive groups according to the morphological immunophenotypic characteristics of the infiltrating tumour cells: (I) myelomonocytic cell tumours (MMCTs, $43 \%$ of CMML patients) consisting of myeloid blasts that were positive for CD68 and/or myeloperoxidase (MPO) but negative for dendritic cell markers; (II) mature plasmacytoid dendritic cell (PDC) proliferations (MPDCPs, $38 \%$ of CMML patients) consisting of mature PDCs positive for CD123, TCL1, and CD303; (III) blastic PDC neoplasms (BPDCNs, 10\% of CMML patients) mainly composed of monomorphous medium-sized blast cells that were positive for CD4, CD56, CD123 and TCL-1; and (IV) blastic indeterminate dendritic cell tumours (BIDCTs, $10 \%$ of CMML patients) consisting of large blast cells that were positive for CD1a, CD4, CD13, CD33, CD56 and S100 protein but were negative for langerin, CD123 and TCL-1. The authors emphasized that PDCs could be a precursor of indeterminate dendritic cells (IDCs) and that IDCs could be a precursor of Langerhans cells, suggesting that the dendritic cell lineage plays an important role in the spectrum of lesions (18). PDCs, also called "plasmacytoid T-cells" or "plasmacytoid monocytes", were discovered very early in CMML $(43,44)$ and are derived from the differentiation of myelomonocytic cells (45). Magro et al. described the clinical and pathological features of 11 patients with cutaneous myeloid dendritic cell dyscrasia, 
two of whom had CMML (22). Since then, cases of similar pathological types of CMML patients with skin involvement have been reported sporadically in the literature (26). There have also been solitary reports of skin infiltration of "tumour-forming PDCs" and "indeterminate cells" expanding the spectrum of skin lesions in CMML with LC $(21,23)$, which remain to be fully elucidated in terms of the pathological features and mechanism in future research. Interestingly, the immunophenotype of the skin lesions may be discordant with the immunohistochemical profile in the BM $(24,42)$.

\section{Prognosis}

CMML is a clonal myeloid neoplasm with features of MDS and MPNs and has an inherent risk for transformation to AML. The extramedullary involvement of AML is most notably present as myeloid sarcoma (also termed granulocytic sarcoma, chloroma, or myeloblastoma), central nervous system leukaemia and LC (46). LC, as one of the main forms of extramedullary myeloid neoplasm, rarely occurs in CMML compared to in AML. Thus far, a variety of chromosomal abnormalities have been reported in patients with AML with extramedullary involvement (41), and although AML with $\mathrm{t}(8 ; 21)$ has been classified into a favourable-risk group, it still has a higher incidence of extramedullary involvement and has a worse prognosis compared to other AML subtypes (47). In CMML, numerous prognostic models have been used to predict survival, such as the MD Anderson prognostic scoring system (MDAPS), CMML-specific prognostic scoring system (CPSS), Mayo Prognostic Model (MPM), Groupe Francais des Myelodysplasies (GFM), and Mayo Molecular Model (MMM) (48). Among these, the CPSS categorizes patients into three groups: high risk (trisomy 8, chromosome 7 abnormalities, or complex karyotype), intermediate risk (all chromosomal abnormalities, except for those in the high- and low-risk categories), and low risk (normal karyotype or $-\mathrm{Y}$ ), with 5-year overall survival (OS) rates of $4 \%, 26 \%$, and $35 \%$, respectively (1). However, it is not clear whether cytogenetic abnormalities or gene mutations are related to the prognosis of CMML with LC, and related reports are very rare (Table 3). In Mathew's study with $108 \mathrm{CMML}$ patients, the overall median survival of 11 patients with LC was much shorter (28.2 months) than that of the remaining 97 patients who never developed LC (44 months); the study concluded that the specific skin lesions could be a predictor of disease progression or potential transformation to AML and were associated with a worse prognosis (17). Furthermore, a more contemporary study of $42 \mathrm{CMML}$ patients with LC found that the BIDCT subtype had a worse prognosis compared to the other three groups (18). From the above study and previous solitary case reports, we found that approximately $50 \%(6 / 12)$ of patients with chromosomal abnormalities experienced conversion to AML (Table 3). Data on gene mutations in CMML with skin infiltration are even rarer in the literature. Skin pathology showed IDC tumours with $K R A S$-positive results, as reported by Loghavi et al. (23) Moreover, Federmann et al. reported three CMML patients with granulomatous dermatitis accompanied by $S R S F 2$ mutation, and whether the SRSF2 mutations contributed to the development of granulomatous dermatitis in the patients still needs to be elucidated (49). A 58-yearold CMML patient seen in our department in 2016 presented with LC as an initial manifestation accompanied by TET2 positivity; this patient eventually died due to transformation to AML in just three months (27). The most frequent genetic mutations in CMML include TET2 ( 60\%), SRSF2 ( 50\%), and ASXL1 ( 40\%), with only frameshift and nonsense ASXL1 mutations independently and adversely impacting OS (50), whereas TET2 and SRSF2 mutations are associated with prognosis (48). Moreover, TET2 mutations in the absence of clonal ASXL1 mutations (ASXL1wt/TET2mt) had a favourable impact on OS in a recent study, and the exact mechanism behind this interaction is unclear (51). The probable reason is that TET2 mutations correlate with changes in DNA methylation in CMML, which lead to better responses to hypomethylating agents (52). In summary, LC has most often been described as a predictor of disease progression and is associated with worse survival outcomes compared to those of patients without LC. Different pathological subtypes of LC have different prognoses. The relationship between cytogenetic or molecular abnormalities and the prognostic value of LC in CMML needs to be fully studied in large-sample clinical trials.

\section{Treatment}

For LC, as the manifestation of the extramedullary infiltration of leukaemia, the treatment is aimed at eradicating the primary underlying disease because leukaemic cells in the BM will continue to reseed the skin if the BM is not in remission (40). Allogeneic stem cell 
Table 3 Cytogenetic abnormalities in CMML patients with leukemia cutis

\begin{tabular}{|c|c|c|c|c|c|}
\hline Reference & Age/Sex & Chromosome abnormality & $\begin{array}{l}\text { Genetic } \\
\text { mutations }\end{array}$ & Progression $^{1}$ & EM \\
\hline $\begin{array}{l}\text { Longacre et al. } \\
\text { (10) }\end{array}$ & $42 / F$ & 46,XX,der(3),t(8;16)(pll.2;q|3.3) & * & * & * \\
\hline $\begin{array}{l}\text { Mahmood et al. } \\
\text { (15) }\end{array}$ & $95 / F$ & Trisomy 8 & * & * & * \\
\hline \multirow{3}{*}{$\begin{array}{l}\text { Mathew et al. } \\
\text { (17) }\end{array}$} & $66 / \mathrm{M}$ & $46, \mathrm{XY}, \operatorname{del}(11)(\mathrm{q} 13 q 23)[12] / 47, \mathrm{XY}, \mathrm{del}(11),+21[8]$ & * & No & * \\
\hline & $74 / \mathrm{M}$ & $\begin{array}{l}47, \mathrm{XY},+\operatorname{mar}[7] / 49, \mathrm{XY},+11,+2 \operatorname{mar}[2] / 49, \mathrm{XY}, \mathrm{i}(11) \\
(\mathrm{q} 10),+2 \operatorname{mar}[1] / 46, \mathrm{XY}[10]\end{array}$ & * & AML & * \\
\hline & $69 / \mathrm{M}$ & $46, \mathrm{XY}, \mathrm{t}(15 ; 17)(\mathrm{q} 22 \mathrm{q} 21)[20]$ & * & * & CNS \\
\hline \multirow{6}{*}{ Vitte et al. (18) } & $76 / \mathrm{M}$ & $47, X Y,+8[12] / 46, X Y[13]$ & * & AML & * \\
\hline & $5 / \mathrm{M}$ & $\begin{array}{l}46, X Y, t(5 ; 13)(q 13-q 15 ; q 12-q 13), \operatorname{add}(6)(q 13) \\
{[29] / 46, X Y[14]}\end{array}$ & * & No & * \\
\hline & $65 / \mathrm{M}$ & 46,XY,del(13)(q14q22)[20] & * & No & * \\
\hline & $60 / \mathrm{M}$ & $46, \mathrm{XY}, \operatorname{del}(7)(\mathrm{q} 11.2)[13] / 47, \mathrm{XY},+21[1] / 46, \mathrm{XY}[8]$ & * & No & * \\
\hline & $83 / \mathrm{M}$ & $\begin{array}{l}\text { 47,XY,dup(3)(q2?1q2?6),+8[6]/46,XY[17]ish(dup)(3) } \\
\text { (wcp3+)[5/20] }\end{array}$ & * & AML & * \\
\hline & $59 / F$ & $47, X X,+8[25]$ & * & No & * \\
\hline
\end{tabular}

*, not clearly described in the literature. M/F, male or female; 1 , transformation to acute myelogenous leukemia (AML) or disease progression; EM, Extramedullary manifestations; CNS, central nervous system; JMML, Juvenile myelomonocytic leukemia; CMML, chronic myelomonocytic leukaemia.

transplantation (ASCT) is a unique potentially curative option for CMML regardless of skin involvement. However, due to the rarity of LC in CMML, which predominantly occurs in older patients with comorbidities, ASCT still remains controversial; only a minority of patients are candidates for transplantation, and few patients benefit from it (1). When transplantation is not feasible, the main treatments for MP-CMML are hypomethylating agents (such as azacitidine and decitabine), cytoreductive therapy (hydroxyurea and other cytotoxic drugs), and supportive care, including erythropoiesis-stimulating agents and transfusions; MD-CMML patients are usually managed as are those with MDS (53). When the BM is in remission but
LC is persistent, long-term control of skin involvement is critical to effectively prevent blasts reseeding from the BM. Therefore, radiotherapy (RT), such as total skin electron beam (TSEB) therapy for diffuse skin involvement, can be an important part of treatment (54-56). There is no evidence that RT confers any benefit when patients obtain a complete response in the BM and skin after chemotherapy, although local RT for skin lesions is sometimes used for palliative care (56). Moreover, for aleukaemic LC, which predates abnormalities of the $\mathrm{PB}$ and $\mathrm{BM}$, some experts recommend that intensive systemic chemotherapy and RT can be used, based on the limited literature $(41,57)$. Given the excessive toxicity, caution should be used to avoid overlapping RT 
and intensive chemotherapy, especially TSEB $(56,58)$. Recently, in terms of the effectiveness of different doses of RT for the treatment of LC, Elsayad et al. conducted a cohort study and found that patients with AML had a better survival rate than patients with other types of leukaemia (59). Nevertheless, we found that the skin lesions of CMML generally did not respond well to RT in previous case reports, and even if the lesions did initially respond rapidly to RT, the lesions recurred after a short period, especially as the disease progressed. This finding indicates that CMML patients with LC have a predisposition to extramedullary relapses. Although there are many treatments for CMML with LC, the response rates and survival rates following therapy are largely unsatisfactory (17). Therefore, further research into new therapy regimens and subsequent clinical trials are encouraged.

\section{Conclusions}

We reviewed the literature on CMML with LC, analysed the clinical and histological characteristics of the disease and underscored the importance of the timely and accurate identification of suspected skin lesions. CMML with LC has a high risk of conversion to AML, and the high mortality rate requires coordination of care by dermatologists, oncologists, and pathologists in the clinical setting. The early diagnosis of LC followed by the prompt initiation of aggressive chemotherapy aimed at eradicating the underlying haematological malignancy may improve the prognosis of leukaemic transformation in CMML. Skin biopsy is mandatory to differentiate between specific (malignant) and non-specific (nonmalignant) lesions. While these currently available treatments can improve patient symptoms, they largely fail to modify the disease evolution and prognosis. Improving the understanding of the molecular pathogenesis of LC in CMML will hopefully lead to the exploration of novel potentially curative therapeutic regimens.

\section{Acknowledgments}

We sincerely thank Yanfei Wang for his help in the language of this article.

Funding: None.

\section{Footnote}

Reporting Checklist: The authors have completed the
Narrative Review reporting checklist. Available at http:// dx.doi.org/10.21037/tcr-19-2882

Conflicts of Interest: All authors have completed the ICMJE uniform disclosure form (available at http://dx.doi. org/10.21037/tcr-19-2882). The authors have no conflicts of interest to declare.

Ethical Statement: The authors are accountable for all aspects of the work in ensuring that questions related to the accuracy or integrity of any part of the work are appropriately investigated and resolved.

Open Access Statement: This is an Open Access article distributed in accordance with the Creative Commons Attribution-NonCommercial-NoDerivs 4.0 International License (CC BY-NC-ND 4.0), which permits the noncommercial replication and distribution of the article with the strict proviso that no changes or edits are made and the original work is properly cited (including links to both the formal publication through the relevant DOI and the license). See: https://creativecommons.org/licenses/by-nc-nd/4.0/.

\section{References}

1. Patnaik MM, Tefferi A. Chronic myelomonocytic leukemia: 2018 update on diagnosis, risk stratification and management. Am J Hematol 2018;93:824-40.

2. Li AW, Yin ES, Stahl M, et al. The skin as a window to the blood: Cutaneous manifestations of myeloid malignancies. Blood Rev 2017;31:370-88.

3. Cho-Vega JH, Medeiros LJ, Prieto VG, et al. Leukemia cutis. Am J Clin Pathol 2008;129:130-42.

4. Duguid JK, Mackie MJ, McVerry BA. Skin infiltration associated with chronic myelomonocytic leukaemia. Br J Haematol 1983;53:257-64.

5. Eubanks SW, Patterson JW. Subacute myelomonocytic leukemia--an unusual skin manifestation. J Am Acad Dermatol 1983;9:581-4.

6. Pozo-Román T, Javier Menarguez-Palanca F, GomezPineda A, et al. Specific cutaneous involvement in the course of chronic myelomonocytic leukemia simultaneously with blastic leukemic transformation. Report of a case with histologic and cytochemical study. J Am Acad Dermatol 1985;12:943-8.

7. Copplestone JA, Oscier DG, Mufti GJ, et al. Monocytic skin infiltration in chronic myelomonocytic leukaemia. Clin Lab Haematol 1986;8:115-9. 
8. Doutre MS, Beylot C, Bioulac P, et al. Skin presentation of chronic myelomonocytic leukaemia resembling cutaneous lymphomas. J R Soc Med 1990;83:593-4.

9. Horiuchi $Y$, Masuzawa M, Nozaki O, et al. Unusual cutaneous lesions associated with chronic myelomonocytic leukaemia. Clin Exp Dermatol 1992;17:121-4.

10. Longacre TA, Smoller BR. Leukemia cutis. Analysis of 50 biopsy-proven cases with an emphasis on occurrence in myelodysplastic syndromes. Am J Clin Pathol 1993;100:276-84.

11. O'Connell DM, Fagan WA, Skinner SM, et al. Cutaneous involvement in chronic myelomonocytic leukemia. Int J Dermatol 1994;33:628-31.

12. Braga D, Manganoni AM, Boccaletti V, et al. Specific skin infiltration as first sign of chronic myelomonocytic leukemia with an unusual phenotype. J Am Acad Dermatol 1996;35:804-7.

13. McCollum A, Bigelow CL, Elkins SL, et al. Unusual skin lesions in chronic myelomonocytic leukemia. South Med J 2003;96:681-4.

14. Dyachenko P, Rozenman D, Bennett M. Unusual skin and testicular lesions in a patient with CMML. Eur J Intern Med 2006;17:290-1.

15. Mahmood S, Cooper A, Ireland R, et al. Leukaemia cutis with chronic myelomonocytic leukaemia. Br J Haematol 2009; 147:413.

16. Takeuchi S, Akasaka E, Rokunohe D, et al. Leukemia cutis is an early sign of blast transformation that may mimic a common skin disease: sycosis-like eruptions in chronic myelomonocytic leukemia. J Dermatol 2010;37:916-8.

17. Mathew RA, Bennett JM, Liu JJ, et al. Cutaneous manifestations in CMML: Indication of disease acceleration or transformation to AML and review of the literature. Leuk Res 2012;36:72-80.

18. Vitte F, Fabiani B, Benet C, et al. Specific skin lesions in chronic myelomonocytic leukemia: a spectrum of myelomonocytic and dendritic cell proliferations: a study of 42 cases. Am J Surg Pathol 2012;36:1302-16.

19. Martínez-Leboráns L, Victoria-Martinez AM, TorregrosaCalatayud JL, et al. Leukemia Cutis: A Report of 17 Cases and a Review of the Literature. Actas Dermosifiliogr 2016;107:e65-9.

20. Zhu H, Lu X, Zhang L. Leukemia Cutis in Chronic Myelomonocytic Leukemia. Am J Med Sci 2016;351:111.

21. Dargent JL, Henne S, Pranger D, et al. Tumor-forming plasmacytoid dendritic cells associated with myeloid neoplasms. Report of a peculiar case with histopathologic features masquerading as lupus erythematosus. J Cutan
Pathol 2016;43:280-6.

22. Magro CM, Momtahen S, Verma S, et al. Cutaneous myeloid dendritic cell dyscrasia: A cutaneous clonal monocytosis associated with chronic myeloproliferative disorders and peripheral blood monocytosis. Ann Diagn Pathol 2016;25:85-91.

23. Loghavi S, Curry JL. Chronic myelomonocytic leukemia masquerading as cutaneous indeterminate dendritic cell tumor: Expanding the spectrum of skin lesions in chronic myelomonocytic leukemia. journal of cutaneous pathology 2017;44:1075-9.

24. Claßen A, Kitz J, Perske C, et al. Leukemia cutis in a patient with chronic myelomonocytic leukemia. J Dtsch Dermatol Ges 2018;16:81-3.

25. Li L, Wang Y, Lian CG, et al. Clinical and pathological features of myeloid leukemia cutis. An Bras Dermatol 2018;93:216-21.

26. Paolino G, Rovere-Querini P, Bearzi P, et al. Relapsing/remitting skin involvement in a patient with chronic myelomonocytic leukemia. Int J Dermatol 2019;58:e170-2.

27. Qiao Y, Zhao L, Jian J, et al. Chronic myelomonocytic leukaemia: leukaemia cutis predicts disease progression. $\mathrm{Br}$ J Hosp Med (Lond) 2019;80:542-3.

28. Resnik KS, Brod BB. Leukemia cutis in congenital leukemia. Analysis and review of the world literature with report of an additional case. Arch Dermatol 1993;129:1301-6.

29. Zhang IH, Zane LT, Braun BS, et al. Congenital leukemia cutis with subsequent development of leukemia. J Am Acad Dermatol 2006;54:S22-7.

30. Bénet C, Gomez A, Aguilar C, et al. Histologic and immunohistologic characterization of skin localization of myeloid disorders: a study of 173 cases. Am J Clin Pathol 2011;135:278-90.

31. Su WP. Clinical, histopathologic, and immunohistochemical correlations in leukemia cutis. Semin Dermatol 1994;13:223-30.

32. Gil-Mateo MP, Miquel FJ, Piris MA, et al. Aleukemic "leukemia cutis" of monocytic lineage. J Am Acad Dermatol 1997;36:837-40.

33. Schwonzen M, Kuehn N, Vetten B, et al. Phenotyping of acute myelomonocytic (AMMOL) and monocytic leukemia (AMOL): association of T-cell-related antigens and skin-infiltration in AMOL. Leuk Res 1989;13:893-8.

34. Kuwabara H, Nagai M, Yamaoka G, et al. Specific skin manifestations in CD56 positive acute myeloid leukemia. J Cutan Pathol 1999;26:1-5. 
35. Wintzen M, Kluin PM, den Ottolander GJ. Specific cutaneous infiltrate caused by Staphylococcus aureus in a patient with chronic myelomonocytic leukemia. Ann Hematol 2000;79:402-4.

36. Saffie M, Sun D, Hsia C. Sweet's syndrome in chronic myelomonocytic leukemia. Am J Hematol 2013;88:630.

37. Vadillo M, Jucgla A, Podzamczer D, et al. Pyoderma gangrenosum with liver, spleen and bone involvement in a patient with chronic myelomonocytic leukaemia. $\mathrm{Br} \mathrm{J}$ Dermatol 1999;141:541-3.

38. Sung CC, Chang PY, Wu YY, et al. Pyoderma gangrenosum as initial presentation of chronic myelomonocytic leukemia. Eur J Haematol 2009;82:410.

39. Wagner G, Fenchel K, Back W, et al. Leukemia cutis - epidemiology, clinical presentation, and differential diagnoses. J Dtsch Dermatol Ges 2012;10:27-36.

40. Parsi M, Go MS, Ahmed A. Cancer, Leukemia Cutis. StatPearls. Treasure Island (FL): StatPearls Publishing StatPearls Publishing LLC, 2019.

41. Bakst RL, Tallman MS, Douer D, et al. How I treat extramedullary acute myeloid leukemia. Blood 2011;118:3785-93.

42. Cronin DM, George TI, Sundram UN. An updated approach to the diagnosis of myeloid leukemia cutis. Am J Clin Pathol 2009;132:101-10.

43. Harris NL, Demirjian Z. Plasmacytoid T-zone cell proliferation in a patient with chronic myelomonocytic leukemia. Histologic and immunohistologic characterization. Am J Surg Pathol 1991;15:87-95.

44. Baddoura FK, Hanson C, Chan WC. Plasmacytoid monocyte proliferation associated with myeloproliferative disorders. Cancer 1992;69:1457-67.

45. Wilson CS, Medeiros LJ. Extramedullary Manifestations of Myeloid Neoplasms. Am J Clin Pathol 2015;144:219-39.

46. Slomowitz SJ, Shami PJ. Management of extramedullary leukemia as a presentation of acute myeloid leukemia. J Natl Compr Canc Netw 2012;10:1165-9.

47. Park SS, Yoon JH, Kim HJ, et al. Characteristics and Survival Outcome Analysis of Extramedullary Involvement in Adult Patients With $\mathrm{t}(8 ; 21)$ Acute Myeloid Leukemia. Clin Lymphoma Myeloma Leuk 2017;17:38-45.e2.

48. Cui Y, Tong H, Du X, et al. Impact of TET2, SRSF2, ASXL1 and SETBP1 mutations on survival of patients with chronic myelomonocytic leukemia. Exp Hematol
Oncol 2015;4:14.

49. Federmann B, Bonzheim I, Yazdi AS, et al. Generalized palisaded neutrophilic and granulomatous dermatitis-a cutaneous manifestation of chronic myelomonocytic leukemia? A clinical, histopathological, and molecular study of 3 cases. Hum Pathol 2017;64:198-206.

50. Patnaik MM, Tefferi A. Cytogenetic and molecular abnormalities in chronic myelomonocytic leukemia. Blood Cancer J 2016;6:e393.

51. Patnaik MM, Lasho TL, Vijayvargiya P, et al. Prognostic interaction between ASXL1 and TET2 mutations in chronic myelomonocytic leukemia. Blood Cancer J 2016;6:e385.

52. Palomo L, Malinverni R, Cabezon M, et al. DNA methylation profile in chronic myelomonocytic leukemia associates with distinct clinical, biological and genetic features. Epigenetics 2018;13:8-18.

53. Alfonso A, Montalban-Bravo G, Garcia-Manero G. Current management of patients with chronic myelomonocytic leukemia. Curr Opin Oncol 2017;29:79-87.

54. Rubin CM, Arthur DC, Meyers G, et al. Leukemia cutis treated with total skin irradiation. Cancer 1985;55:2649-52.

55. Pepek JM, Paulino AC, Briones MA, et al. Role of total skin electron beam therapy for leukemia cutis in pediatric patients. Pediatr Blood Cancer 2008;50:1054-5.

56. Bakst R, Yahalom J. Radiation therapy for leukemia cutis. Pract Radiat Oncol 2011;1:182-7.

57. Imanaka K, Fujiwara K, Satoh K, et al. A case of aleukemic monocytic leukemia cutis treated with total body electron therapy. Radiat Med 1988;6:229-31.

58. Solberg LA Jr, Wick MR, Bruckman JE. Doxorubicinenhanced skin reaction after whole-body electronbeam irradiation for leukemia cutis. Mayo Clin Proc 1980;55:711-5.

59. Elsayad K, Oertel M, Haverkamp U, et al. The effectiveness of radiotherapy for leukemia cutis. J Cancer Res Clin Oncol 2017;143:851-9.

Cite this article as: Qiao Y, Jian J, Deng L, Tian H, Liu B. Leukaemia cutis as a specific skin involvement in chronic myelomonocytic leukaemia and review of the literature. Transl Cancer Res 2020;9(8):4988-4998. doi: 10.21037/tcr-19-2882 